\title{
Potentially Inappropriate Medication in Community-Dwelling Primary Care Patients who were Screened Positive for Dementia
}

\author{
Diana Wucherer ${ }^{\mathrm{a}, *}$, Tilly Eichler ${ }^{\mathrm{a}}$, Johannes Hertel ${ }^{\mathrm{a}, \mathrm{b}}$, Ingo Kilimann ${ }^{\mathrm{c}, \mathrm{d}}$, Steffen Richter ${ }^{\mathrm{a}}$, \\ Bernhard Michalowsky $^{\mathrm{a}}$, Jochen René Thyrian ${ }^{\mathrm{a}}$, Stefan Teipel ${ }^{\mathrm{c}, \mathrm{d}}$ and Wolfgang Hoffmann ${ }^{\mathrm{a}, \mathrm{e}}$ \\ ${ }^{a}$ German Center for Neurodegenerative Diseases (DZNE), Rostock/Greifswald, Greifswald, Germany \\ ${ }^{\mathrm{b}}$ Department of Psychiatry and Psychotherapy, University Medicine Greifswald, Greifswald, Germany \\ ${ }^{\mathrm{c}}$ German Center for Neurodegenerative Diseases (DZNE), Rostock/Greifswald, Rostock, Germany \\ ${ }^{\mathrm{d}}$ Department of Psychosomatic Medicine, University of Rostock, Rostock, Germany \\ ${ }^{\mathrm{e}}$ Department of Epidemiology of Health Care and Community Health, Institute for Community Medicine, \\ University Medicine Greifswald, Greifswald, Germany
}

Accepted 29 August 2016

\begin{abstract}
.
Background: Potentially inappropriate medication (PIM) in older people is a risk factor for adverse drug effects. This risk is even higher in older people with dementia (PWD).

Objective: Our study aimed to determine (1) the prevalence of PIM among primary care patients who were screened positive for dementia and (2) the sociodemographic and clinical variables associated with the use of PIM.

Methods: DelpHi-MV (Dementia: life- and person-centered help in Mecklenburg-Western Pomerania) is a general practitioner-based, cluster-randomized, controlled intervention study to implement and evaluate an innovative concept of collaborative dementia care management in Germany. The comprehensive baseline assessment includes a home medication review. The present analyses are based on the data from 448 study participants (age 70+, DemTect $<9$ ). PIMs were identified using the list of Potentially Inappropriate Medications in the Elderly (Priscus).

Results: (1) A total of 99 study participants (22\%) received at least one PIM. The highest prevalence was found for antidepressants, benzodiazepines, and analgetics. The most frequently prescribed PIMs were amitriptyline, etoricoxib, and doxazosin.

(2) Use of a PIM was significantly associated with a diagnosis of a mental or behavioral disorder.

Conclusions: The prescription rate of PIMs for community-dwelling PWD was comparable with the rates found for the general population of older people in Germany (20-29\%). Antidepressants with anticholinergic properties and long-acting benzodiazepines were the most prescribed PIMs, despite having an unfavorable benefit-risk ratio. This high prevalence of PIM prescriptions in a vulnerable population of PWD indicates that standard care for dementia should include careful medication review and management.
\end{abstract}

Keywords: Dementia, PIM List, potentially inappropriate medications, primary health care

ClinicalTrials.gov Identifier: NCT01401582

\footnotetext{
${ }^{*}$ Correspondence to: Diana Wucherer, German Center for Neurodegenerative Diseases (DZNE), Rostock/Greifswald, Ellern-
} 


\section{INTRODUCTION}

Pharmacotherapy in the elderly is complex and a challenge to health care providers, as up to $77 \%$ of older people are affected by multiple chronic diseases $[1,2]$. Polypharmacy associated with multimorbidity increases the risk of adverse drug events (ADE), such as medication-related hospitalizations, and higher health care costs [3-6]. The high rates of medication in the elderly and the associated risk for ADE have triggered the development of criteria to identify a potentially inappropriate medication (PIM). Laroche et al. defined PIM as "a drug for which the risk of an ADE outweighs the clinical benefit, particularly when there is evidence in favor of a safer or more effective alternative therapy for the same condition" [7]. The most well-known PIM list is the American Beers criteria [8], last updated in 2015 [9]. Because of the differences in the drug markets between the USA and the European Union, such PIM lists need to be adapted for national use. The German list of PIM for the elderly (Priscus list) was established in line with the international PIM lists [7, 8, 10, 11] and published in 2010, aiming to reduce the rate of ADE and to provide higher medication safety [12]. According to previous studies, the prevalence of PIM in the general elderly population in Germany ranged from $20 \%$ to $29 \%$ [13-17]. More than half of the PIMs in the Priscus list are declared as inappropriate for the treatment of people with dementia (PWD) due to side effects in the central nervous system that may worsen cognitive impairment. In addition, adverse effects on the physical functions that reduce the patient's ability to perform everyday tasks [12, 18-22]. For instance, long-term exposure to benzodiazepines and anticholinergic medications is associated with an increased risk for drug-induced delirium, a negative influence on cognition, and an increased risk of falls [23-26]. Little is known about the prevalence of PIM in community-dwelling PWD in Germany. Our study aims to determine (1) the prevalence of PIM according to the Priscus list in community-dwelling primary care patients who were screened positive for dementia and (2) the sociodemographic and clinical variables associated with the use of PIM.

\section{MATERIALS AND METHODS}

\section{Study design}

The present cross-sectional analysis is based on data from the DelpHi-MV (Dementia: life- and person-centered help in Mecklenburg-Western Pomerania) trial, a GP (general practitioner)-based, cluster-randomized, controlled intervention trial to implement and evaluate an innovative concept of collaborative dementia care management in Germany [27, 28]. Inclusion criteria for the trial were: 70 years or older in age, living at home, screening for probable dementia is positive (DemTect <9) [29]. People were systematically screened for these inclusion criteria in participating GP practices. People fulfilling these criteria provided written informed consent for participation. If a patient was unable to give written informed consent, then the form was signed by his or her legal representative (as approved by the Ethical Committee of the Chamber of Physicians of Mecklenburg-Western Pomerania, registry number BB 20/11). All participants were contacted to arrange a baseline assessment at the person's home. Two to four home visits were necessary for the baseline assessment. The comprehensive standardized baseline assessment included a computer-based home medication review (HMR) among other assessments [30]. The HMR was conducted by Dementia Care Managers (DCM) - the study-qualified nurses [31].

\section{Participants}

The present analysis is based on the data of 448 participants who participated in the DelpHi-MV study with a complete baseline medication assessment. Figure 1 shows the CONSORT flow chart of the DelpHi-MV study for the baseline assessment.

\section{Data analyses}

To analyze the associations between the sociodemographic and clinical variables and the occurrence of PIM variables, the following factors were considered: age, sex, living situation (alone/not alone), cognitive status, functional status, depressive symptoms, visit to a specialist (neurologist/psychiatrist [yes/no]), total number of drugs taken, formal diagnosis of dementia, and number of comorbid diagnoses. The severity of cognitive impairment was assessed using the Mini-Mental State Examination (MMSE) [32]. The severity was categorized as "no indication of cognitive impairment" (score 27-30), "mild" (20-26), "moderate" (10-19), or "severe" (0-9) cognitive impairment [33]. Depressive symptoms were assessed using the Geriatric Depression Scale (GDS) and categorized as "no depression" (score $0-5$ ) or 


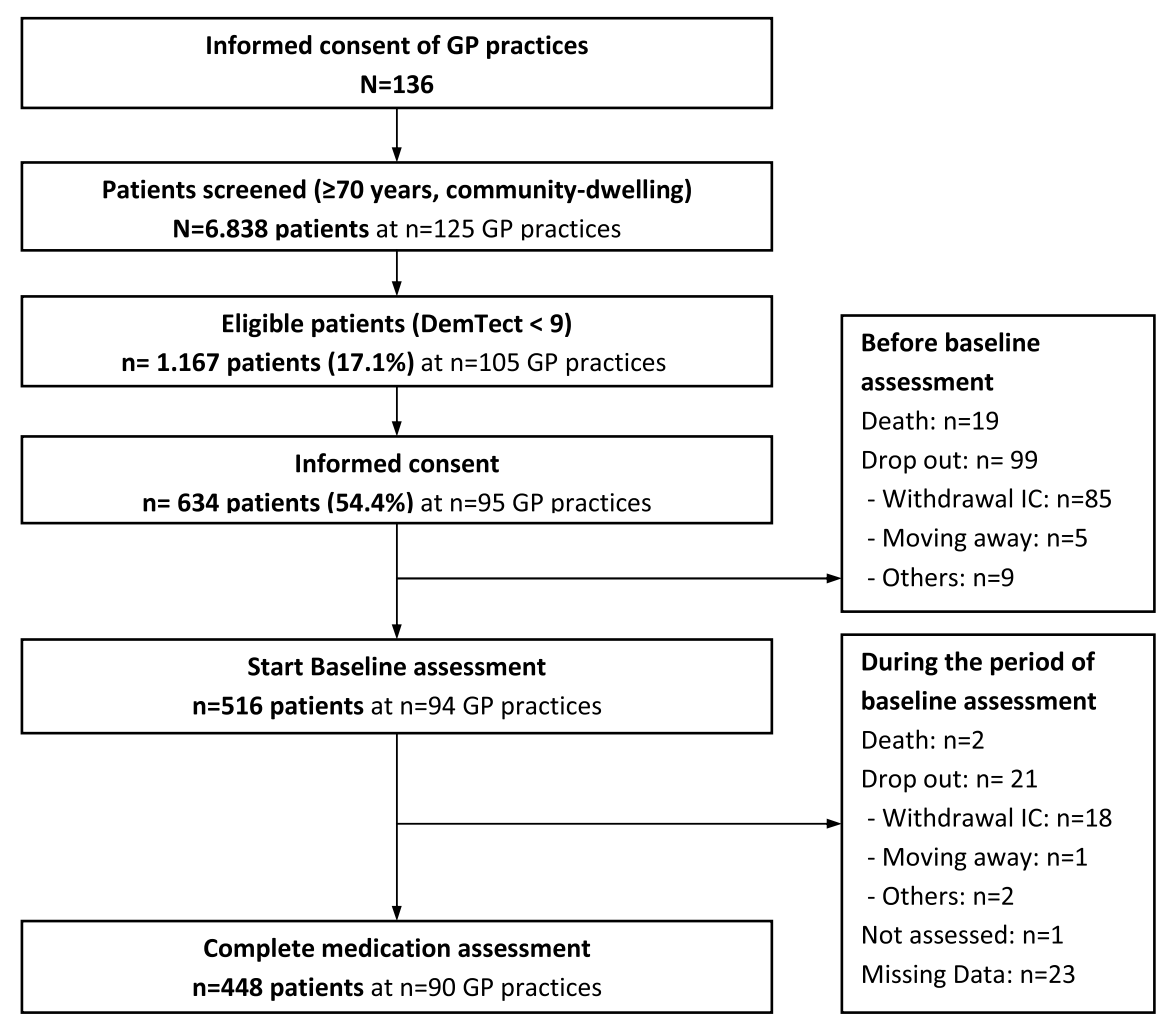

Fig. 1. CONSORT flow chart of DelpHi-MV study.

"possible depression" (score 6-15) [34, 35]. The functional status was assessed using the Bayer Activities of Daily Living Scale (B-ADL) [36, 37], which yields a mean score between 1 and 10 , where 1 indicates the lowest and 10 the highest possible impairment. In accordance with the International Classification of Diseases and Related Health Problems (ICD-10, German Modification) [38], medical diagnoses were retrieved from the medical records of the treating GP. A dementia diagnosis refers to any of the following ICD-10 codes: F00/G30 (dementia due to Alzheimer's disease), F01 (vascular dementia), F02 (dementia in other diseases), F03 (unspecified dementia), or G31 (other degenerative diseases of nervous system, not otherwise classified). Diagnosis of mental and behavioral disorders refers to the ICD-10 codes F04-F69. The computerbased home medication anamnesis solicited the study participant's entire medication history (prescription drugs and over-the-counter drugs). Active substances were coded to the Anatomical Therapeutic Chemical (ATC) classification system [39]. Topical agents and homeopathic and anthroposophic medications were not considered in this analysis.

\section{Identification of PIM}

PIMs were identified using the Priscus list [12]. This German PIM list, which was developed in 2010, takes into account the international PIM lists $[7,8,10$, 11] and contains 83 active substances from 18 substance classes. The Priscus list contains suggestions for treatment alternatives and measures that should be taken if the respective drug cannot be discontinued (e.g., monitoring laboratory values or dose adjustment). The list names specific diseases for which certain drugs should not be used.

\section{Descriptive statistics}

The variables for the patient sample were summarized using descriptive statistics. Metric variables were expressed by means and standard deviation, nominal variables by proportions. For continuous variables, Welch $t$-tests were used in univariate analysis, comparing the individuals with PIM prescription to individuals without PIM, for nominal variables Fisher's exact test was used. Note, that the $p$-values must be treated with care as these tests do not take 
into account the stochastic dependency of patients who were recruited by the same GP.

\section{Multivariate statistics}

We fitted logistic regression models to evaluate which variables were associated with PIM use which was the dependent variable in these models. The sociodemographic factors (age, sex, living situation) and the total number of drugs were used as covariates and were included to attenuate possible confounding factors, the clinical variables (cognitive status, functional status, depressive symptoms, diagnosis of dementia) were the independent variables of interest. As the clinical variables depend on each other they were tested simultaneously in the described model on significance via a Wald-Test. In a second model, we included the number of diagnosed mental and behavioral disorders (F04-F69) and the number of other comorbidities additionally to the before used variables exploring the effects of these two variables on PIM prescription and the coefficients of the other variables. To account for the clustering of participants who were recruited by the same GP, we applied a conditional (fixed-effect) logistic regression model, which offers consistent estimates of clustered data $[40,41]$. Before running the final regression model, we checked for non-linear relations using the multivariate fractional polynomial procedure [42]. However, we found no indication of non-linear relationships. The estimation procedure excluded 114 observations because of the invariance in the outcome-variable in the respective clusters (that is, all or none of the patients treated by the same GP received a PIM). We found no significant differences between the included and excluded cases regarding the covariates analyzed (see Supplementary Table 3), but the frequency of PIM prescription use differed significantly between these groups, as expected. The final regression analysis was performed for the remaining 334 cases belonging to 44 clusters (clusters were unbalanced). The standard errors of the regression coefficients were estimated using the bootstrapping technique with 2000 replications, which provides appropriate estimates of standard errors in complex samples [43]. Statistical analyses were performed using STATA ${ }^{\circledR} 13$ [44].

\section{RESULTS}

\section{Sociodemographic and clinical characteristics of the study population}

The sociodemographic and clinical characteristics of the study population are summarized in Table 1.

There were no significant differences regarding age, sex, and the DemTect score among the patients included in the analysis and those who dropped out of the study (see Supplementary Table 1). Regarding the variables age, Priscus PIMs taken, and sex, there were no significant differences observed between patients included in the analyses and those excluded

Table 1

Sociodemographic and clinical characteristics of the study population

\begin{tabular}{|c|c|c|c|c|c|c|}
\hline & Total sample & PIM & no PIM & $t$ & df & $p$ \\
\hline & $n=448$ & $n=99$ & $n=349$ & & & \\
\hline Age, mean (SD) & $79.9(5.43)$ & $79.7(5.51)$ & $79.9(5.41)$ & 0.327 & 156.76 & $0.744^{\mathrm{a}}$ \\
\hline Sex (female), $n(\%)$ & $259(57.8)$ & $66(66.7)$ & $193(55.3)$ & & & $0.050^{b}$ \\
\hline Living situation (living alone), $n(\%)$ & $222(49.6)$ & $51(51.5)$ & $171(50.0)$ & & & $0.733^{\mathrm{b}}$ \\
\hline Severity of dementia (MMSE), mean (SD) & $22.5(5.01)$ & $23.3(4.55)$ & $22.3(5.12)$ & -1.83 & 176.15 & $0.069^{\mathrm{a}}$ \\
\hline No cognitive impairment (score, $27-30), n(\%)$ & $106(23.7)$ & $25(25.3)$ & $81(23.2)$ & & & \\
\hline Mild cognitive impairment (score, 20-26), $n(\%)$ & $236(52.7)$ & $56(56.6)$ & $180(51.6)$ & & & \\
\hline Moderate cognitive impairment (score, 10-19), $n(\%)$ & 97 (21.7) & $17(17.2)$ & $80(23.0)$ & & & \\
\hline Severe cognitive impairment (score, $0-9), n(\%)$ & $9(2.0)$ & $1(1.0)$ & $8(2.3)$ & & & \\
\hline Diagnosis of dementia (ICD-10: F00-F03/G30/G31), $n(\%)$ & $168(37.5)$ & $27(27.3)$ & $141(40.4)$ & & & $0.019^{b}$ \\
\hline $\begin{array}{l}\text { Diagnosis of mental and behavioral disorders (ICD-10: } \\
\text { F04-F69), mean (SD) }\end{array}$ & $0.39(0.79)$ & $0.59(1.00)$ & $0.33(0.72)$ & -2.32 & 129.00 & $0.022^{\mathrm{a}}$ \\
\hline Previous visit to specialist (neurologist/psychiatrist), $n(\%)$ & $116(26.0)$ & $33(33.3)$ & $83(23.9)$ & & & $0.068^{\mathrm{b}}$ \\
\hline Total number of drugs, mean (SD) & $7.2(3.45)$ & $8.3(3.06)$ & $6.8(3.48)$ & -4.20 & 178.08 & $0.0011^{\mathrm{a}}$ \\
\hline Comorbid diagnoses, mean (SD) & $12.1(7.29)$ & $11.8(6.68)$ & $12.1(7.46)$ & 0.366 & 174.92 & $0.715^{\mathrm{a}}$ \\
\hline Depression (GDS), $n(\%)$ & $72(15.2)$ & $18(17.3)$ & $54(14.6)$ & & & $0.238^{\mathrm{b}}$ \\
\hline Functional status (B-ADL), mean (SD) & $3.6(3.37)$ & $3.4(2.30)$ & $3.6(2.49)$ & 0.732 & 169.84 & $0.465^{\mathrm{a}}$ \\
\hline
\end{tabular}

Standard deviations or percentages are in brackets. MMSE, Mini-Mental State Examination (range 0-30; higher score indicates better cognitive functioning); B-ADL, Bayer Activities of Daily Living Scale (range 0-10; lower score indicates better performance); GDS,

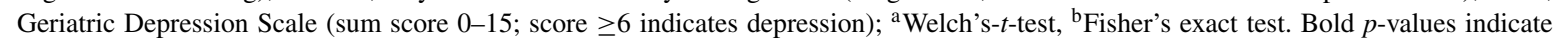
$p<0.05$. 
Table 2

Potentially inappropriate medication according to Priscus criteria

\begin{tabular}{|c|c|c|}
\hline Active substance class & Active substance & $\begin{array}{l}\text { Study participants using } \\
\text { PIM }^{* *} \mathrm{~N}=111\end{array}$ \\
\hline \multirow[t]{4}{*}{ Antiinflammatory and antirheumatic products, non-steroids } & Indometacin & $3(2.7 \%)$ \\
\hline & Ketoprofen & $1(0.9 \%)$ \\
\hline & Meloxicam & $2(1.8 \%)$ \\
\hline & Etoricoxib & $11(9.9 \%)$ \\
\hline Antiarrhythmics, class IC & Flecainide & $2(1.8 \%)$ \\
\hline Cardiac glycosides & Acetyldigoxin & $1(0.9 \%)$ \\
\hline \multirow{2}{*}{ Urologicals, Drugs for urinary frequency and incontinence } & Solifenacin & $7(6.3 \%)$ \\
\hline & Tolterodine & $1(0.9 \%)$ \\
\hline \multirow[t]{3}{*}{ Tricyclic antidepressants } & Amitriptyline & $16(14.4 \%)$ \\
\hline & Doxepin & $4(3.6 \%)$ \\
\hline & Trimipramine & $5(4.5 \%)$ \\
\hline Antiemetics & Dimenhydrinat & $2(1.8 \%)$ \\
\hline Antihypertensives, Antiadrenergic agents, peripherally acting & Doxazosin & $8(7.2 \%)$ \\
\hline \multirow[t]{2}{*}{ Antihypertensives, Antiadrenergic agents, centrally acting } & Clonidine & $1(0.9 \%)$ \\
\hline & Methyldopa & $3(2.7 \%)$ \\
\hline \multirow[t]{2}{*}{ Antipsychotics } & Levomepromazine & $1(0.9 \%)$ \\
\hline & Haloperidol & $2(1.8 \%)$ \\
\hline Dopaminergic agents & Dihydroergocryptine alpha mesilate & $1(0.9 \%)$ \\
\hline Antidementia drugs & Dihydroergotoxine & $1(0.9 \%)$ \\
\hline \multirow[t]{2}{*}{ Muscle relaxants, centrally acting agents } & Baclofen & $3(2.7 \%)$ \\
\hline & Tetrazepam* & $1(0.9 \%)$ \\
\hline \multirow[t]{4}{*}{ Anxiolytics, Benzodiazepine derivatives } & Diazepam & $8(7.2 \%)$ \\
\hline & Medazepam & $3(2.7 \%)$ \\
\hline & Clobazam & $1(0.9 \%)$ \\
\hline & Chlordiazepoxide & $1(0.9 \%)$ \\
\hline Hypnotics and sedatives & Chloral hydrate & $1(0.9 \%)$ \\
\hline Hypnotics and sedatives, Benzodiazepine derivatives & Nitrazepam & $3(2.7 \%)$ \\
\hline \multirow[t]{2}{*}{ Hypnotics and sedatives, Benzodiazepine related drugs } & Zolpidem & $3(2.7 \%)$ \\
\hline & Zopiclone & $4(3.6 \%)$ \\
\hline \multirow[t]{2}{*}{ Antihistamines for systemic use } & Doxylamine & $1(0.9 \%)$ \\
\hline & Diphenhydramine & $2(1.8 \%)$ \\
\hline Psychostimulants, agents used for ADHD and nootropics & Piracetam & $4(3.6 \%)$ \\
\hline Peripheral vasodilators & Naftidrofuryl & $3(2.7 \%)$ \\
\hline Beta blocking agents, non-selective & Sotalol & $1(0.9 \%)$ \\
\hline
\end{tabular}

* Suspension of admission in Europe since 1st August, 2013. ${ }^{* *}$ Double entry possible.

due to missing data, but the patients not included in the analyses due to missing data had a lower DemTect score than those patients in the baseline analysis $(p=0.0001)$ (see Supplementary Table 2).

\section{PIM prevalence}

Of the 448 community-dwelling patients who were screened positive for dementia, a total of 99 study participants (22\%) received at least one PIM according to the Priscus list. Ten study participants took 2 PIMs at the same time; one study participant took 3 PIMs. In regard to substances, there were 34 active substances from the Priscus list in 111 cases (Table 2).

The most commonly used active substance classes of PIMs included the following: tricyclic antidepressants $(n=25 / 111 ; 22.5 \%$ of all PIM in our analysis), benzodiazepine derivatives and benzodiazepine-related drugs $(n=23 / 111 ; 20.7 \%)$, nonsteroidal anti-inflammatory and antirheumatic drugs $(n=17 / 111 ; 15.3 \%)$, drugs for urinary frequency and incontinence $(n=8 / 111 ; 7.2 \%)$, and peripherally acting antiadrenergic agents $(n=8 / 111$; 7.2\%). The most common PIMs were amitriptyline ( $n=16 ; 14.4 \%$ of all PIMs (111) in our analysis), etoricoxib $(n=11 / 111 ; 9.9 \%)$, doxazosin $(n=8 / 111$; $7.2 \%)$, diazepam $(n=8 / 111 ; 7.2 \%)$, and solifenacin $(n=7 / 111 ; 6.3 \%)$. None of the study participants in the subgroup taking amitriptyline were diagnosed with neuropathic pain according to the medical records of the treating GP. The remaining active agents from all other drug classes constituted approximately $17 \%$ of the prescribed PIMs (Table 2).

\section{Factors associated with PIM use}

The results of the multivariate conditional fixedeffects logistic regression analyses $(n=334$ patients 
Table 3

Factors associated with PIM use

\begin{tabular}{|c|c|c|c|c|c|c|c|c|}
\hline & $\begin{array}{c}\text { No PIM } \\
n=244\end{array}$ & $\begin{array}{c}\text { PIM } \\
n=90\end{array}$ & OR & $\begin{array}{l}\text { Bootstrap } \\
\text { Std. Err. }\end{array}$ & $\mathrm{z}$ & $p$ & $95 \% \mathrm{CI}$ & \\
\hline Age, mean (SD) & $80.1(5.62)$ & $79.2(5.31)$ & 0.96 & 0.025 & -1.54 & 0.125 & 0.91 & 1.01 \\
\hline Sex (female), $n(\%)$ & $135(55.3)$ & $59(65.6)$ & 1.97 & 0.718 & 1.87 & 0.062 & 0.966 & 4.03 \\
\hline Living situation (living alone), $n(\%)$ & $119(48.8)$ & $47(52.2)$ & 1.10 & 0.39 & 0.27 & 0.791 & 0.55 & 2.19 \\
\hline Cognitive impairment (MMSE), mean (SD) & $22.4(5.05)$ & $23.5(4.18)$ & 1.01 & 0.033 & 0.40 & 0.689 & 0.95 & 1.08 \\
\hline Functional status (B-ADL), mean (SD) & $3.5(2.33)$ & $3.3(2.27)$ & 1.00 & 0.086 & 0.03 & 0.972 & 0.85 & 1.19 \\
\hline Depression (GDS), $n(\%)$ & $34(70.8)$ & $14(29.2)$ & 1.15 & 0.506 & 0.31 & 0.759 & 0.48 & 2.72 \\
\hline Number of drugs, mean (SD) & $7.0(3.50)$ & $8.3(3.15)$ & 1.11 & 0.060 & 2.02 & 0.043 & 1.00 & 1.24 \\
\hline Dementia diagnosis, $n(\%)$ & $102(41.8)$ & $23(25.6)$ & 0.58 & 0.237 & -1.33 & 0.183 & 0.26 & 1.29 \\
\hline
\end{tabular}

Multivariate conditional fixed-effects logistic regression analysis $(n=334$ patients assigned to $n=44$ clusters $)$ : Wald chi ${ }^{2}(8)=11.08$, $p=0.1971$. Data presented as mean \pm standard deviation or $n(\%)$. OR, odds ratio; CI, confidence interval; MMSE, Mini-Mental State Examination (range 0-30; higher score indicates better cognitive functioning); B-ADL, Bayer Activities of Daily Living Scale (range 0-10; lower score indicates better performance); GDS, Geriatric Depression Scale (sum score 0-15; score $\geq 6$ indicates depression). Bold $p$-values indicate $p<0.05$.

Table 4

Factors associated with PIM use, considering of diagnosis of mental and behavioral disorders and other comorbid diagnoses

\begin{tabular}{|c|c|c|c|c|c|c|c|c|}
\hline & $\begin{array}{l}\text { No PIM } \\
n=244\end{array}$ & $\begin{array}{c}\text { PIM } \\
n=90\end{array}$ & OR & $\begin{array}{l}\text { Bootstrap } \\
\text { Std. Err. }\end{array}$ & $\mathrm{z}$ & $p$ & $95 \% \mathrm{CI}$ & \\
\hline Age, mean (SD) & $80.1(5.62)$ & $79.2(5.31)$ & 0.98 & 0.027 & -1.21 & 0.228 & 0.92 & 1.02 \\
\hline Sex (female), $n(\%)$ & $135(55.3)$ & $59(65.6)$ & 1.78 & 0.707 & 1.46 & 0.145 & 0.82 & 3.88 \\
\hline Living situation (living alone), $n(\%)$ & $119(48.8)$ & $47(52.2)$ & 1.09 & 0.406 & 0.23 & 0.814 & 0.53 & 2.26 \\
\hline Cognitive impairment (MMSE), mean (SD) & $22.4(5.05)$ & $23.5(4.18)$ & 1.02 & 0.035 & 0.71 & 0.480 & 0.96 & 1.10 \\
\hline Functional status (B-ADL), mean (SD) & $3.5(2.33)$ & $3.3(2.27)$ & 1.00 & 0.091 & -0.02 & 0.984 & 0.84 & 1.19 \\
\hline Depression (GDS), $n(\%)$ & $34(70.8)$ & $14(29.2)$ & 1.22 & 0.540 & 0.44 & 0.660 & 0.51 & 2.90 \\
\hline Number of drugs, mean (SD) & $7.0(3.50)$ & $8.3(3.15)$ & 1.13 & 0.080 & 1.77 & 0.077 & 0.99 & 1.30 \\
\hline Dementia diagnosis, $n(\%)$ & $102(41.8)$ & $23(25.6)$ & 0.59 & 0.234 & -1.34 & 0.181 & 0.27 & 1.28 \\
\hline $\begin{array}{l}\text { Diagnosis of mental and behavioral disorders } \\
\text { (ICD-10: F04-F69), mean (SD) }\end{array}$ & $0.3(0.7)$ & $0.6(1.0)$ & 1.59 & 0.300 & 2.47 & 0.014 & 1.10 & 2.30 \\
\hline Comorbid diagnoses, mean (SD) & $12.4(7.2)$ & $12.4(6.7)$ & 0.96 & 0.0367 & -1.00 & 0.316 & 0.89 & 1.04 \\
\hline
\end{tabular}

Multivariate conditional fixed-effects logistic regression analysis $(n=334$ patients assigned to $n=44$ clusters $):$ Wald $\mathrm{chi}^{2}(10)=22.77$, $p=0.0116$. Data presented as mean \pm standard deviation or $n(\%)$. OR, odds ratio; CI, confidence interval; MMSE, Mini-Mental State Examination (range 0-30; higher score indicates better cognitive functioning); B-ADL, Bayer Activities of Daily Living Scale (range 0-10; lower score indicates better performance); GDS, Geriatric Depression Scale (sum score 0-15; score $\geq 6$ indicates depression). Bold $p$-values indicate $p<0.05$.

assigned to $n=44$ clusters) are shown in Tables 3 and 4 . The results of the first multivariate conditional logistic regression also showed that the prescription of a PIM was significantly and positively associated with the total number of drugs taken (OR: 1.11; 95\% CI: $1.00-1.24 ; p=0.043$ ) (Table 3). None of the clinical variables (cognitive status, functional status, depressive symptoms, diagnosis of dementia) was significant, neither alone, nor in a Wald-Test, testing all coefficients of these variables simultaneously on zero $\left(\operatorname{chi}^{2}(4)=4.01, p=0.4031\right)$. The regression model failed to reach a global significance (Wald $\left.\operatorname{chi}^{2}(8)=11.08, p=0.1971\right)$. Therefore, the result regarding the number of drugs taken must be treated carefully. In a second logistic regression model, which included the number of diagnosed mental and behavioral disorders (F04-F69) and the number of comorbidities as additional predictors, the prescription of a PIM was significantly positively associated with a diagnosis of a mental or behavioral disorder (OR: 1.59; 95\% CI: 1.10-2.30; $p=0.014$ ) (Table 4). Accordingly, the second model reached significance (Wald $\operatorname{chi}^{2}(10)=22.77, p=0.0116$ ), underlining the predictive value of psychiatric comorbidities for the prescription of a PIM. The association with the total number of drugs taken was no longer significant in the second model, although the effect size was in the same range as that for the first model (OR: $1.13 ; 95 \%$ CI: $0.99-1.30 ; p=0.070$ ).

\section{DISCUSSION}

\section{PIM in community-dwelling people who were screened positive for dementia}

Using primary data, we analyzed the prevalence and correlates of PIM prescriptions according to the Priscus list in community-dwelling GP patients who 
were screened positive for dementia in Germany. Approximately $22 \%$ of the patients who were screened positive for dementia received at least one PIM listed in the Priscus list. The prevalence rate of PIM prescriptions in our sample is consistent with the results from previous studies that used the Priscus list and found prevalence rates for PIM use in the general German population ( $\geq 65$ years of age) between $20 \%$ and $29 \%$ [13-17, 45]. In a prospective multicenter study involving a French cohort of community-dwelling Alzheimer's disease patients (REAL.FR) [46], the prevalence of PIM prescriptions was $47 \%$ according to the Laroche list [7] but $25 \%$ according to the Beers list [8]. The authors conceded that the prevalence of PIM prescriptions in community-dwelling PWD in France was comparable to that in the elderly population in general. However, because of the differences between the national PIM lists, a direct international comparison of the prevalence of PIM prescriptions with our findings is difficult.

In the AGnES study, which was a communitybased, prospective cohort study with home-visit patients, the prevalence of Priscus PIM prescriptions amounted to $27 \%$ in the subgroup of patients who were screened positive for dementia [45]. This prevalence rate is slightly higher compared to that in our results, despite the higher degree of comorbidity in the DelpHi-MV cohort (mean number of 12 compared to 6 comorbid diagnoses per patient). This could be explained by the fact that our data collection started after the publication of the Priscus list, and PIM use in the general population has declined since then.

Tricyclic antidepressants with anticholinergic properties (amitriptyline, trimipramine, doxepin) were the most frequently prescribed PIMs in our analysis (23\% of all PIM). This finding is in accordance with a recent Australian study that reported anticholinergics and sedatives as the most commonly prescribed PIM in community-dwelling patients of memory clinics with a diagnosis of mild cognitive impairment or dementia [47]. Amitriptyline, the most frequent active agent in our analysis (14\% of all PIM), is often used to treat neuropathic pain and is inexpensive. This might explain why amitriptyline was the most frequently prescribed PIM in most studies using the Priscus in Germany [14, 45]. However, none of the study participants using amitriptyline in our analysis had a diagnosis of neuropathic pain by their treating GP in their medical records. It is likely that psychiatric symptoms, such as depres- sive mood or insomnia, were common reasons for amitriptyline prescriptions in the DelpHi-MV-cohort. At $4 \%$ ( $n=17 / 448$ study participants), the prevalence of benzodiazepine derivatives in our study was lower than that in a previous French study that found an $8.5 \%$ prevalence for long-acting benzodiazepines in older people with dementia [46]. Benzodiazepines (in our sample: diazepam, medazepam, clobazam, chlordiazepoxide, nitrazepam) and benzodiazepinerelated drugs (in our sample: zolpidem, zopiclone) are often used in older adults for the treatment of insomnia, depression, or anxiety. In addition, they are used often to treat behavioral symptoms of dementia, despite the lack of evidence for their effectiveness [48].

In summary, in contrast to guidelines and recommendations [33], anticholinergics and benzodiazepines were the most common PIM prescriptions in our analysis. This is consistent with previous evidence suggesting that patients with cognitive impairment and dementia have a higher prevalence of anticholinergic and sedative drug prescriptions than matched controls [25, 49].

Fifteen percent of the prescribed PIMs were antiinflammatory and antirheumatic substances from the Priscus list (etoricoxib, indometacin, meloxicam, ketoprofen), which are associated with an increased risk of gastrointestinal bleeding, ulceration, or perforation, and renal adverse drug effects [12]. The PIMs in this group must be carefully interpreted because, in some cases, treatment with these drugs might be the only option for the patient after considering the individual's health status, possible interactions, and other factors.

The present analysis included the complete medication history of the study participants (prescription drugs and over-the-counter drugs). The considerable percentage of over-the-counter drugs is often missing from studies based on secondary (e.g., reimbursement) data alone. The prevalence of over-the-counter PIM (OTC-PIM) was $4.5 \%$ for participants who used PIM. OTC-PIMs included the non-prescription hypnotics (doxylamine, diphenhydramine) and antiemetics (dimenhydrinat). These antihistamines for systemic use are also potentially inappropriate for older people owing to their adverse cognitive effects $[9,50]$. Patients or their caregivers rarely inform their GPs about the use of OTC; therefore, it is difficult for physicians to monitor OTC-PIMs and their adverse drug reactions or to estimate their risks of interactions with prescribed medication. 


\section{Factors associated with PIM use}

The results of the multivariate conditional logistic regression analysis showed that the diagnosis of mental or behavioral disorder was significantly associated with PIM use in community-dwelling people who were screened positive for dementia. This can be explained by the fact that many psychotropic substances used to treat mental and behavioral disorders are included in the PIM lists. This is in line with the study of Mann et al. conducted in Austrian nursing home residents, in which neuropsychiatric symptoms were described as a risk factor for PIM use and suggested that neuropsychiatric symptoms rather than cognitive impairments provoked PIM prescriptions [51]. The severity of cognitive impairment (measured by the MMSE score) was not associated with the risk of taking a Priscus PIM in our analysis. This result agrees with previous German and international studies that also failed to find associations between cognitive impairments or dementia and PIM use [49].

In contrast, German studies on PIM use in the general population aged over 65 years found that the female sex, age, depression, and the number of drugs taken (polypharmacy) were risk factors for PIM use $[13,52,53]$. The female sex and polypharmacy were identified as risk factors for PIM use in communitydwelling elders with dementia in Germany, as well as internationally [45, 46, 54]. In our univariate model, there were equally significant associations between female sex, having a formal diagnosis of dementia, polypharmacy, and PIM use. However, these results were not found in the final multivariate model, thus suggesting confounds by other factors.

\section{Limitations}

The prevalence of PIM use was analyzed as yes/no, regardless of the frequency of PIM use (regular use or only when required). Because of the data collection method, this analysis could not examine medications in the Priscus list that had dosage specifications. Any dose of a PIM drug was counted as a Priscus PIM (0 for none, 1 for one or more PIMs). Therefore, the PIM prevalence might have been somewhat overestimated in this analysis. Patients who were excluded from the analyses due to missing data had more severe cognitive impairment than the patients that were included, as determined by the DemTect score. This might have biased the results. The PIM prevalence was higher in patients included in the regression analysis compared to those excluded due to invariance in the outcome variables in their respective cluster. Therefore, patients with a lower PIM rate were somewhat under-represented in the regression analysis. Because the DelpHi-MV cohort included mostly patients with mild dementia and just a few patients with severe dementia, the effect of severe dementia on the prescription rates of PIM might have been represented insufficiently. The cognitive screening for identification of dementia can lead to both false negatives (e.g., in more highly educated patients) and false positives (e.g., in less educated patients). The rate of falsepositive diagnoses in our study might have been lower than $24 \%$ [55]. That is, the results might have been distorted and should be interpreted with caution.

\section{Conclusion}

The results of the present analyses show that the prevalence of PIM prescriptions in communitydwelling primary care patients who were screened positive for dementia was comparable to the prevalence in the general older population in Germany. The presence of a diagnosis of a mental or behavioral disorder in patients who were screened positive for dementia was the only factor associated with increased PIM use in a multivariate model. Further research should examine whether the presence of a mental/behavioral disorder in people without dementia does have such an impact on PIM in the elderly. Cognitive impairment was not a risk factor for a PIM prescription. Certainly, the individual therapeutic decision of the treating physician may differ from the recommendations of the Priscus list because of other factors that need to be considered, such as the patient's anamnesis, comorbidities, prognostic estimates, individual needs, and prescriptions of cotreating physicians [15]. Nevertheless, there is a clear potential for an enhanced medication management of PWD, especially regarding drugs with anticholinergic properties and long-acting benzodiazepines for chronic use. Further analysis of our follow-up data will determine the impact of medication management on the reduction of PIM use in community-dwelling primary care patients who were screened positive for dementia.

\section{ACKNOWLEDGMENTS}

Present analysis is a part of the DelpHi-MV (Dementia: life- and person-centered help in Mecklenburg-Western Pomerania) study and was performed by the German Center of Neurode- 
generative Diseases (DZNE), University Medicine Greifswald, and University Medicine Rostock.

We would like to thank all study participants, their caregiver, general practitioners, and pharmacists for the good cooperation. We would also like to thank the following various specialists contributed to the development of the study (in alphabetical order): Ines Abraham, Kerstin Albuerne, Aniela Angelow, Grit Assmann, Vaska Boehmann, Georgia Boewing, Kathleen Dittmer, Thomas Fiss, Daniel Fredrich, Sarah Gardzella, Jana Hubert, Ulrike Kempe, Viktoria Kim-Boese, Julius Krause, Saskia Moll, Andrea Pooch, Melanie Reimann, Sabine Schmidt, Frederike Schreiber, Christiane Schnick, Christine Winckler, Paula Winter.

Authors' disclosures available online (http://j-alz. com/manuscript-disclosures/16-0581r2).

\section{SUPPLEMENTARY MATERIAL}

The supplementary material is available in the electronic version of this article: http://dx.doi.org/ 10.3233/JAD-160581.

\section{REFERENCES}

[1] Barnett K, Mercer SW, Norbury M, Watt G, Wyke S, Guthrie B (2012) Epidemiology of multimorbidity and implications for health care, research, and medical education: A crosssectional study. Lancet 380, 37-43.

[2] Bähler C, Huber CA, Brungger B, Reich O (2015) Multimorbidity, health care utilization and costs in an elderly community-dwelling population: A claims data based observational study. BMC Health Serv Res 15, 23.

[3] Scott I, Jayathissa S (2010) Quality of drug prescribing in older patients: Is there a problem and can we improve it? Intern Med J 40, 7-18.

[4] Walsh EK, Cussen K (2010) "Take ten minutes": A dedicated ten minute medication review reduces polypharmacy in the elderly. Ir Med J 103, 236-238.

[5] van den Berg N, Meinke-Franze C, Fiss T, Hoffmann W (2013) Changes in blood pressure in patients with hypertension in the context of delegated GP-home visits: A prospective implementation study. Blood Press Monit 18, 63-71.

[6] Davies EA, O’Mahony MS (2015) Adverse drug reactions in special populations - the elderly. Br J Clin Pharmacol 80, 796-807.

[7] Laroche ML, Charmes JP, Bouthier F, Merle L (2009) Inappropriate medications in the elderly. Clin Pharmacol Ther 85, 94-97.

[8] Beers MH (1997) Explicit criteria for determining potentially inappropriate medication use by the elderly. An update. Arch Intern Med 157, 1531-1536.

[9] American Geriatrics Society (2015) American Geriatrics Society 2015 updated Beers Criteria for potentially inappropriate medication use in older adults. J Am Geriatr Soc 63, 2227-2246.
[10] Fick DM, Cooper JW, Wade WE, Waller JL, Maclean JR, Beers MH (2003) Updating the Beers criteria for potentially inappropriate medication use in older adults: Results of a US consensus panel of experts. Arch Intern Med 163, 27162724.

[11] McLeod PJ, Huang AR, Tamblyn RM, Gayton DC (1997) Defining inappropriate practices in prescribing for elderly people: A national consensus panel. CMAJ 156, 385-391.

[12] Holt S, Schmiedl S, Thurmann PA (2010) Potentially inappropriate medications in the elderly: The PRISCUS list. Potenziell inadäquate Medikation für ältere Menschen: Die PRISCUS-Liste. Dtsch Arztebl Int 107, 543-551.

[13] Zimmermann T, Kaduszkiewicz H, van den Bussche H, Schon G, Brettschneider C, Konig HH, Wiese B, Bickel H, Mosch E, Luppa M, Riedel-Heller S, Werle J, Weyerer S, Fuchs A, Pentzek M, Hanisch B, Maier W, Scherer M, Jessen F (2013) [Potentially inappropriate medication in elderly primary care patients : A retrospective, longitudinal analysis]. Bundesgesundheitsblatt Gesundheitsforschung Gesundheitsschutz 56, 941-949.

[14] Amann U, Schmedt N, Garbe E (2012) Prescribing of potentially inappropriate medications for the elderly: An analysis based on the PRISCUS list. Dtsch Arztebl Int 109, 69-75.

[15] Siebert S, Elkeles B, Hempel G, Kruse J, Smollich M (2013) The PRISCUS list in clinical routine. Practicability and comparison to international PIM lists. Z Gerontol Geriatr 46, 35-47.

[16] Thiem U, Hinrichs T, Muller CA, Holt-Noreiks S, Nagl A, Bucchi C, Trampisch U, Moschny A, Platen P, Penner E, Junius-Walker U, Hummers-Pradier E, Theile G, Schmiedl S, Thurmann PA, Scholz S, Greiner W, Klaassen-Mielke R, Pientka L, Trampisch HJ (2011) Prerequisites for a new health care model for elderly people with multiple morbidities: Results and conclusions from 3 years of research in the PRISCUS consortium. Z Gerontol Geriatr 44(Suppl 2), 101-112.

[17] Thürmann PA, Holt-Noreiks S, Nink K, Zawinell A (2012) Arzneimittelversorgung älterer patienten. In Versorgungsreport 2012, Günster C, Klose J, Schmacke N, eds. Stuttgart, pp. 111-130.

[18] Koyama A, Steinman M, Ensrud K, Hillier TA, Yaffe K (2014) Long-term cognitive and functional effects of potentially inappropriate medications in older women. $J$ Gerontol A Biol Sci Med Sci 69, 423-429.

[19] Jessen F, Wiese B, Bachmann C, Eifflaender-Gorfer S, Haller F, Kolsch H, Luck T, Mosch E, van den BH, Wagner M, Wollny A, Zimmermann T, Pentzek M, Riedel-Heller SG, Romberg HP, Weyerer S, Kaduszkiewicz H, Maier W, Bickel H (2010) Prediction of dementia by subjective memory impairment: Effects of severity and temporal association with cognitive impairment. Arch Gen Psychiatry 67, 414422.

[20] Jessen F, Wolfsgruber S, Wiese B, Bickel H, Mosch E, Kaduszkiewicz H, Pentzek M, Riedel-Heller SG, Luck T, Fuchs A, Weyerer S, Werle J, van den BH, Scherer M, Maier W, Wagner M (2014) AD dementia risk in late MCI, in early $\mathrm{MCI}$, and in subjective memory impairment. Alzheimers Dement 10, 76-83.

[21] Gray SL, Anderson ML, Dublin S, Hanlon JT, Hubbard R, Walker R, Yu O, Crane PK, Larson EB (2015) Cumulative use of strong anticholinergics and incident dementia: A prospective cohort study. JAMA Intern Med 175, 401-407.

[22] Fox C, Smith T, Maidment I, Chan WY, Bua N, Myint PK, Boustani M, Kwok CS, Glover M, Koopmans I, Camp- 
bell N (2014) Effect of medications with anti-cholinergic properties on cognitive function, delirium, physical function and mortality: A systematic review. Age Ageing 43, 604-615.

[23] Tannenbaum C, Paquette A, Hilmer S, Holroyd-Leduc J, Carnahan R (2012) A systematic review of amnestic and non-amnestic mild cognitive impairment induced by anticholinergic, antihistamine, GABAergic and opioid drugs. Drugs Aging 29, 639-658.

[24] Billioti de Gage S, Begaud B, Bazin F, Verdoux H, Dartigues JF, Peres K, Kurth T, Pariente A (2012) Benzodiazepine use and risk of dementia: Prospective population based study. BMJ 345, e6231.

[25] Roe CM, Anderson MJ, Spivack B (2002) Use of anticholinergic medications by older adults with dementia. $J$ Am Geriatr Soc 50, 836-842.

[26] Campbell NL, Boustani MA (2015) Adverse cognitive effects of medications: Turning attention to reversibility. JAMA Intern Med 175, 408-409.

[27] Thyrian JR, Fiss T, Dreier A, Bowing G, Angelow A, Lueke S, Teipel S, Flessa S, Grabe HJ, Freyberger HJ, Hoffmann W (2012) Life- and person-centred help in MecklenburgWestern Pomerania, Germany (DelpHi): Study protocol for a randomised controlled trial. Trials 13, 56.

[28] Eichler T, Thyrian JR, Dreier A, Wucherer D, Kohler L, Fiss T, Bowing G, Michalowsky B, Hoffmann W (2014) Dementia care management: Going new ways in ambulant dementia care within a GP-based randomized controlled intervention trial. Int Psychogeriatr 26, 247-256.

[29] Calabrese P, Kessler J (2000) Screening for cognitive impairment in dementia - the DemTect procedure. Eur Neuropsychopharmacol $\mathbf{1 0}, 369$.

[30] Fiss T, Thyrian JR, Wucherer D, Assmann G, Kilimann I, Teipel SJ, Hoffmann W (2013) Medication management for people with dementia in primary care: Description of implementation in the DelpHi study. BMC Geriatr 13, 121.

[31] Dreier A, Hoffmann W (2013) [Dementia Care Manager for patients with dementia. Determination of the requirements and qualifications contents for nurses in the DelpHi-MV study]. Bundesgesundheitsblatt Gesundheitsforschung Gesundheitsschutz, 56, 1398-1409.

[32] Kessler J, Markowitsch HJ, Denzler P (1990) Mini-MentalStatus-Test (MMST) [German Version], Beltz Test GmbH, Göttingen.

[33] Deutsche Gesellschaft für Psychiatrie, Psychotherapie und Nervenheilkunde (DGPPN): S3-Leitlinie "Demenzen", https://www.dgppn.de/fileadmin/user_upload/_medien/down load/pdf/kurzversion-leitlinien/REV_S3-leiltlinie-demenz en.pdf, Last updated August 2015, Accessed 18 September 2015.

[34] Gauggel S, Birkner B (1999) Validity and reliability of a German version of the Geriatric Depression Scale (GDS). Z Klin Psychol Forsch Praxis 28, 18-27.

[35] Yesavage JA, Brink TL, Rose TL, Lum O, Huang V, Adey M, Leirer VO (1982) Development and validation of a geriatric depression screening scale: A preliminary report. $J$ Psychiatr Res 17, 37-49.

[36] Erzigkeit H, Lehfeld H, Pena-Casanova J, Bieber F, Yekrangi-Hartmann C, Rupp M, Rappard F, Arnold K, Hindmarch I (2001) The bayer-activities of daily living scale (B-ADL): Results from a validation study in three European countries. Dement Geriatr Cogn Disord 12, 348-358.
[37] Hindmarch I, Lehfeld H, de Jongh P, Erzigkeit H (1998) The bayer activities of daily living scale (B-ADL). Dement Geriatr Cogn Disord 9(Suppl 2), 20-26.

[38] Deutsches Institut für medizinische Dokumentation und Information (DIMDI): Internationale statistische Klassifikation der Krankheiten und verwandter Gesundheitsprobleme, German Modification, https://www. dimdi.de/static/de/klassi/icd-10-gm/kodesuche/onlinefassu ngen/htmlgm2016/, Last updated 21 December 2015, Accessed 28 January 2016.

[39] GKV-Arzneimittelindex im Wissenschaftlichen Institut der AOK (WidO) des AOK-Bundesverbandes GbR: Anatomisch-therapeutisch-chemische Klassifikation mit Tagesdosen (ATC), Amtliche Fassung des ATC-Index mit DDD-Angaben für den deutschen Arzneimittelmarkt, http: //www.wido.de/arz_atcddd-klassifi.html, Last updated April 2016, Accessed 20 May 2016.

[40] Breslow N, Day N (1980) Statistical methods in cancer research. Vol 1. The analysis of case-control studies. (IARC Scientific Publication no. 32), International Agency for Research on Cancer, Lyon.

[41] Hosmer D, Lemeshow S, Sturdivant R (2013) Applied logistic regression, John Wiley \& Sons, New Jersey.

[42] Royston P, Sauerbrei W (2008) Multivariable ModelBuilding - A pragmatic approach to regression analysis based on fractional polynomials for continuous variables, John Wiley \& Sons, New York.

[43] Efron B, Tibshiran R (1986) Boostrap measures for standard errors, confidence intervals and other measures of statistical accuracy, Stat. Sci.

[44] StataCorp (2014) StataCorp LP, College Station, TX.

[45] Fiss T, Thyrian JR, Fendrich K, van den BN, Hoffmann W (2013) Cognitive impairment in primary ambulatory health care: Pharmacotherapy and the use of potentially inappropriate medicine. Int J Geriatr Psychiatry 28, 173-181.

[46] Montastruc F, Gardette V, Cantet C, Piau A, Lapeyre-Mestre M, Vellas B, Montastruc JL, Andrieu S (2013) Potentially inappropriate medication use among patients with Alzheimer disease in the REAL.FR cohort: Be aware of atropinic and benzodiazepine drugs! Eur J Clin Pharmacol 69, 1589-1597.

[47] Cross AJ, George J, Woodward MC, Ames D, Brodaty H, Ilomaki J, Elliott RA (2016) Potentially inappropriate medications and anticholinergic burden in older people attending memory clinics in Australia. Drugs Aging 33, 37-44.

[48] Tampi RR, Tampi DJ (2014) Efficacy and tolerability of benzodiazepines for the treatment of behavioral and psychological symptoms of dementia: A systematic review of randomized controlled trials. Am J Alzheimers Dis Other Demen 29, 565-574.

[49] Johnell K (2015) Inappropriate drug use in people with cognitive impairment and dementia: A systematic review. Curr Clin Pharmacol 10, 178-184.

[50] Campbell N, Perkins A, Hui S, Khan B, Boustani M (2011) Association between prescribing of anticholinergic medications and incident delirium: A cohort study. J Am Geriatr Soc 59(Suppl 2), S277-S281.

[51] Mann E, Haastert B, Bohmdorfer B, Fruhwald T, Iglseder B, Roller-Wirnsberger R, Meyer G (2013) Prevalence and associations of potentially inappropriate prescriptions in Austrian nursing home residents: Secondary analysis of a cross-sectional study. Wien Klin Wochenschr 125, 180-188. 
[52] Stock S, Redaelli M, Simic D, Siegel M, Henschel F (2014) Risk factors for the prescription of potentially inappropriate medication (PIM) in the elderly: An analysis of sickness fund routine claims data from Germany. Wien Klin Wochenschr 126, 604-612.

[53] Schubert I, Kupper-Nybelen J, Ihle P, Thurmann P (2013) Prescribing potentially inappropriate medication (PIM) in Germany's elderly as indicated by the PRISCUS list. An analysis based on regional claims data. Pharmacoepidemiol Drug Saf 22, 719-727.
[54] Lau DT, Mercaldo ND, Harris AT, Trittschuh E, Shega J, Weintraub S (2010) Polypharmacy and potentially inappropriate medication use among community-dwelling elders with dementia. Alzheimer Dis Assoc Disord 24, 56-63.

[55] Eichler T, Thyrian J, Hertel J, Michalowsky B, Wucherer D, Dreier A, Kilimann I, Teipel S, Hoffmann W (2015) Rates of formal diagnosis of dementia in primary care: The effect of screening. Alzheimers Dement (Amst) 1, 87-93. 